\title{
The Relationship between Early Maladaptive Schemas and Esfahan Guidance School Teachers' Job Burnout
}

\author{
MoradiQahderijani Mahboubeh ${ }^{1}$, Homaei Reza ${ }^{2}$, \\ Mehdizadeh Safoura ${ }^{3}$, Norouzi Mohsen ${ }^{4 *}$
}

\section{ABSTRACT}

Job burnout can lead to staff dissatisfaction and negative effects on the other aspects of their life including social, personal and family aspects. Job burnout psychological syndrome includes emotional exhaustion, depersonalization and reducing the personal performance. Early maladaptive schemas are self-harm emotional and cognitive patterns which have formed at the beginning of the evolution of the mind and are repeated in the course of individual and social life. Teaching is a stressful occupation and if teachers have false beliefs from their past, they will be more at the risk of job burnout. In this study we have dealt with studying the relationship between theearly maladaptive schemas and guidance school teachers' job burnout. This descriptive-correlation study has been done on 312 people who have selected through classified random sampling method with the population of 2422 male and female teachers. The data collection tool included Young maladaptive schemas 75 questions short form (YSQ-SF) and Maslach 22 questions burnout form (MBI).Data were analyzed through correlation coefficient and regression analysis. There was significant and positive correlation between early maladaptive schemas and the job burnout $(r=0 / 05)$. There was also significant and positive correlation between early maladaptive schemas and emotional exhaustion components, personal performance (lack of personal success) and teachers' depersonalization $(r=0 / 05)$. According to the results, early maladaptive schemas play an important role in the occurrence of teachers' job burnout. Teachers should be constantly under psychological counseling.

Keywords: Early maladaptive schemas, Job Burnout, Teachers, Guidance School

Job burnout causes staff dissatisfaction and negative impacts on the other areas of life including social, personal and family affairs (Dolha, 2004). Job burnout is a consequence of mental and physical fatigue which is caused by the constant and ongoing emotional stress resulting from the

\footnotetext{
${ }^{1}$ M.Sc. in Clinical Psychology, Guest professor of Isfahan PayamNour University (PNU), Qahderijan,Isfahan, Iran.

${ }^{2}$ M.Sc. in Exceptional Children Psychology, Educational professor member of Isfahan Payam Nour University (PNU), Qahderijan, Isfahan, Iran

${ }^{3}$ M.Sc. in Business and Financial Management, Yazd University, Yazd, Iran

${ }^{4}$ B.Sc. in Health Care Administration, Isfahan University of Medical Sciences and Healthcare Services (IUMS), Isfahan, Iran

*Corresponding Author

(C) 2015 I M Mahbouben, H Reza, M Safoura, N Mohsen; licensee IJIP. This is an Open Access Research distributed under the terms of the Creative Commons Attribution License (http://creativecommons.org/licenses/by/2.0), which permits unrestricted use, distribution, and reproduction in any Medium, provided the original work is properly cited.
} 


\section{The Relationship between Early Maladaptive Schemas and Esfahan Guidance School Teachers' Job Burnout}

long-term involvement in human (Tubaei, Daghighafkar and Haghshenas, 2009).Maslach(2001) believes that psychological job burnout syndrome includes emotional exhaustion, depersonalization and reducing the personal performance. In his view, the three-dimensional concept of job burnout, emotional exhaustion resulting from stress and the loss of emotional sources can be found in the person. Depersonalization is the negative and cruelly response to the individuals who are usually the receiver of the services and this issue refers to the negative understanding of the client and finally reduction or loss of personal inadequacy, reducing the sense of competence in fulfilling the task and negative self-assessment in relation to achieve the task. One of the most important reasons for leaving the job among teachers is job burnout. This issue is a big damage for investments and also is a big damage for wasting the academic talents. Studies have showed that 5 to 20 percent of the teachers have job burnout (Hakanen, Arnold and Williams, 2006). Talented teachers often get involved in their students and dream unrealistic expectations of what they can do and forget the rest and holidays opportunities. The unrealistic expectations gradually frustrate them and encounter their objectives, practices and their values with hesitation (Farahmand,2007).The information which we take from outside will be interpreted in the complex network of previous knowledge and data. There are almost no understanding from life stimuli and events that are not influenced by the previous one. This is particularly true for processes which require continuous involvement of the cerebral cortex activity. This information is used not only for the understanding and interpretation but also for the anticipation of the situations that are happening in our environment. The schemas are cognitive structures which organize the information processes. In fact they are "filters" or "templates" which we use them for receiving, organizing and processing of the information. Each person takes a set of schemas for understanding his/her own world (Fiske \& Taylor, 1991).

Early maladaptive schemas are self-harm emotional and cognitive patterns which have been formed in the mind at the beginning of the evolution and are repeated in the course of personal and social life. Price, (2012) used the concept of schemas persistence with the job behavior and believed that job stress leads to intensify unconscious conflicts in some employees. Working is hateful for those who have inflexible early maladaptive schemas. These people are prone to stress and job burnout by early maladaptive schemas and also contrast styles. Teaching profession is a stressful profession. Teachers are always concerned about learning and internalizing the subjects, preventing the reduction of learning motivation, the influence of teachings on changes and creating the suitable citizenship and social behaviors in the students. That is why there is always the background of the job burnout prevalence. If there are teachers who have false beliefs from their past and have the early maladaptive schemas, the possibility of the job burnout prevalence will be more. Now this question is raised that are these two variables (early maladaptive schemas

and job burnout) related to each other among Esfahan school teachers? The present study has dealt with studying this issue. 


\section{METHOD}

The research method was descriptive and correlation.

The population: The study population consisted of all teachers in Esfahan guidance school in the academic years 2012-2013 and their number was 2422.

The sample size: The sample size was calculated 331 people through KREJCIE and MORGAN table (1970) but the returned questionnaires were 312 people.

Sampling procedure: Since the number of male and female of Esfahan guidance school teachers was different so it was used classified random sampling.

\section{Measuring tools:}

Maladaptive schemas form: Maladaptive schemas form has prepared by Young (1990). These 75 questions form measures the early maladaptive schemas in 15 components including emotional deprivation, abandonment, mistrust-abuse, social isolation-alienation, failure-shame, failure, incompetence-dependence, vulnerability to harm, illness, involvement, obedience, sacrifice, emotional inhibition, uncompromising standards, entitlement and inadequate self-control-selfdiscipline. Young (1990) has reported the concurrent validity coefficient and the reliability of the form respectively 0.75 and 0.82 .

Job burnout form: This form has prepared by Maslach and Jackson (1981). This form consists of 22 questions that measures the job burnout in the three components; emotional exhaustion, personal performance (personal failure) and depersonalization. Maslach and Jackson (1981) has reported the validity coefficient and the reliability of the form respectively 0.81 and 0.88 .

Statistical methods of data analysis: In order to analyze the data it has been used the correlation coefficient statistical methods and regression analysis. 


\section{RESULTS}

The main hypothesis of this study (first hypothesis): There is a correlation between the early maladaptive schemas and Esfahan guidance school teachers' job burnout.

Table1: The results of Pearson correlation coefficient between the early maladaptive schemas and Esfahan guidance school teachers' job burnout.

\begin{tabular}{|c|c|c|c|c|}
\hline $\begin{array}{c}\text { Significant } \\
\text { level }\end{array}$ & $\begin{array}{c}\text { Determination } \\
\text { coefficient }\end{array}$ & $\mathbf{r}$ & Abundance & Source \\
\hline 0.001 & 0.18 & 0.44 & 312 & $\begin{array}{c}\text { The early maladaptive schemas and Esfahan } \\
\text { guidance school teachers' job burnout }\end{array}$ \\
\hline
\end{tabular}

According to the results (Table1), $\mathrm{r}$ in the level of $\mathrm{P}<=0.05$ shows significant and positive correlation between the early maladaptive schemas and Esfahan guidance school teachers' job burnout.

There is a correlation between the early maladaptive schemas and the components of Esfahan guidance school teachers' job burnout (Table2).

Table 2: The results of Pearson correlation coefficient between the early maladaptive schemas and the components of Esfahan guidance school teachers' job burnout

\begin{tabular}{|c|c|c|c|c|}
\hline $\begin{array}{c}\text { Significant } \\
\text { level }\end{array}$ & $\begin{array}{c}\text { Determination } \\
\text { coefficient }\end{array}$ & $\mathbf{r}$ & Abundance & Source \\
\hline 0.001 & 0.25 & 0.50 & 312 & $\begin{array}{c}\text { The early maladaptive schemas and teachers' } \\
\text { emotional exhaustion }\end{array}$ \\
\hline 0.001 & 0.289 & 0.55 & 312 & $\begin{array}{c}\text { The early maladaptive schemas and personal } \\
\text { performance (personal failure) teachers }\end{array}$ \\
\hline 0.001 & 0.16 & 0.40 & 312 & $\begin{array}{c}\text { The early maladaptive schemas and teachers' } \\
\text { depersonalization }\end{array}$ \\
\hline
\end{tabular}

Table3: The results of job burnout components predictor regression coefficient on the basis of Esfahan guidance school teachers' early maladaptive schemas

\begin{tabular}{|c|c|c|c|c|c|c|}
\hline $\begin{array}{c}\text { Significant } \\
\text { level }\end{array}$ & $\begin{array}{c}\text { Determination } \\
\text { coefficient }\end{array}$ & t value & $\begin{array}{c}\text { Regression } \\
\text { coefficient }\end{array}$ & $\begin{array}{c}\text { Standard } \\
\text { error }\end{array}$ & $\begin{array}{c}\text { Non- } \\
\text { standard } \\
\text { coefficient }\end{array}$ & Source \\
\hline 0.04 & 0.34 & 2.30 & 0.22 & 0.17 & 0.40 & Emotional exhaustion \\
\hline 0.02 & 0.34 & 2.19 & 0.24 & 0.23 & 0.49 & $\begin{array}{c}\text { Personal performance } \\
\text { (personal failure) }\end{array}$ \\
\hline 0.001 & 0.34 & 3.11 & 0.29 & 0.25 & 0.70 & Depersonalization \\
\hline
\end{tabular}




\section{The Relationship between Early Maladaptive Schemas and Esfahan Guidance \\ School Teachers' Job Burnout}

According to the results (Table3), the early maladaptive schemas have an impact on Esfahan guidance school teachers' emotional exhaustion components, personal performance (personal failure) and depersonalization. Determination coefficient shows that the impact of the schemas on the emotional exhaustion, personal performance (personal failure) and teachers depersonalization is about 0.34 .

\section{DISCUSSION}

The correlation between the early maladaptive schemas and Esfahan guidance school teachers' job burnout showed that there is a positive and significant correlation between the early maladaptive schemas and Esfahan guidance school teachers' job burnout. In schemas theory each person uses a set of schemas for understanding his/her own world. If a person did not receive enough love and acceptance from love sources in the childhood, these schemas would be categorize in the maladaptive schemas category which lead to disturb the mental balance by the least stress from environment and causes to increase the stress.

The findings of this study are consistent with the theory of schemes because in the present study it has been reported that if there are the early maladaptive schemas in teachers, it will be more likely to increase the job burnout and also their tolerance threshold towards stress will be reduced much more. Thus the early maladaptive schemas lead to disturb the mental balance. In the present study the term mental imbalance has been reported as job burnout. In Lotfi, Nabaviand Khosravi(2007), Tabatabai, Sohrabi,Zarge and Karimi (2010), Monirpour, Gholami, Zarag and Tamadonfard (2010),Fathi, Soltani, Mokhtari, Mousavi(2010), Izadian (2010), Shirvaninegad and Peyvasteh (2011), Qasemimotlagh (2006), Ball and Cecer (2001), Welburn et al. (2002), Jellian, Mitchellein and Ashleigh (2003),Stiles (2004), Hans, John and Sans (2005), Castile, Proof, Marciz, Smizr, Yoder, Howlet (2007), Wells (2007), Hawk (2011) studies it has been reported that the early maladaptive schemas are contributors for disturbing the mental balance and developing the psychosocial incompatibility.

\section{CONCLUSION}

According to the results of the present study (the relationship between the early maladaptive schemas and teachers' job burnout) and also according to the results of the above-mentioned researches (the relationship between the early maladaptive schemas and mental imbalance and Psychosocial maladaptive) it can be concluded that the early maladaptive schemas play an important role in the prevalence of the burnout. On the other hand, the organizations managers should have paid more attention to this issue and put the staff under continuous psychological counseling so that the effect of the early maladaptive schemas in the job performance is neutralized. 


\section{The Relationship between Early Maladaptive Schemas and Esfahan Guidance \\ School Teachers' Job Burnout}

REFERENCES

Ball, K. and Cecer, T.A. 2001. The dispositional causes of job satisfaction: A core evaluations approach. Research in organizational behavior. 19:151-188.

Castile, K.P. and Howlet, B. 2007.The early maladaptive schemas of self-mutilators. Journal of cognitive psychotherapy. 20:271-291.

Dolha Z. 2001. The burnout. Hamshahri, 15 December, 2592 http://www.hamshahrionline.ir

Farahmand, F. 2007. Stress and burnout in teachers. Havva, Tehran

Fathi, A., Soltani, M., Mokhtari, R. and Mousavi S. 2011.The relationship between personality disorders and early maladaptive schemas in students exposed to trauma. Journal of psychology.No.3.

Fiske, S.T. and Taylor, S.E. 1991. Social cognition (second edition). New York, McGraw Hill

Ghasemi Motlagh, M. 2007. The comparison between early maladaptive schemas in smoking and non-smoking students, Allameh Tabatabai University, Master's thesis, University of Allameh Tabatabai

Hak M. 2007. Later psychological distress: The mediating role of maladaptive schemas. Journal of Child Abuse and neglect33 (1), 59-68

HakanenJari, Arnold I., Shaufeli B. and Wilmar B. (2006), the burnout and work engagement among teachers. Journal ofschool psychology, 43, 495-513

Hans, M. John, M. and Sans, I. (2005), clinical psychology, psychology, psychotherapy. Volume 12 , issue $2.42-149$

Izadian M. (2011), the role of early maladaptive schemas in explaining depression and mental and emotional fatigue. Master's Thesis, Tehran University

Jellian B., Mitchellein M. \& Ashleigh, S. (2003). Cognitive therapy bipolar: ashema focuse approach Australia and New Zealand. Journal of psychiatry, Volume 37 :(1-51)

Lotfi R., Nabavi V. and Khosravi Z. (2008), the comparison between early maladaptive schemas in personality disorders soldiers and healthy soldiers, Army University of Medical Sciences journal, No. 2: 1266-1261

Maslach C., Schaufeli W.B, Leiter M.P (2001), Job burnout, Annual Review of Psychology, 52, 397-422

Monirpour M., Gholami K., Zarge G. and Tamadonfard B. (2011), the role of early maladaptive schemas in anticipating of a personality disorder, University of Medical Sciences journal, twelfth period, No.4

Prays J.G. (2012), Schema-focused and Personality disorder. New England journal of medicine, 364: 2037-41

Shirvaninegad Y. and Peyvasteh M. (2012), Determining the relationship between life satisfaction and early maladaptive schemas in university students. Knowledge and research in Applied Psychology, Year 12th, No. 2, Summer

Stiles L.K. (2004) the tendency to forgive in dating and married couples: The role of attachment and relationship satisfaction .Personal Relationships, 11(3), 373-393.

Tabatabaei, Sohrabi, Zarchi A. and M. Karimi (2011), the effectiveness of training the therapeutic schema experimental techniques on the schema of the isolated and frustrated people, Journal of Medical Sciences University, No. 8, Tenth period

Tubaei SH., Daghighafkar M. and Haghshenas H. (2010), the relationship between job burnout, mental health and personality characteristics of the dentists, journal of dentistry, Shiraz University of Medical Sciences, tenth period, No. 4,winter 2010,pp. 335-348 
Welburn M.E, Bellah C.G., Kilpatrick S.D and Johnson J.L (2002) Vengefulness, There lationships between forgiveness, rumination, well-being and the big five. Personality and Social Psychology Bulletin, 27(5), 601-610

Wells M.O (2007), Emotional maltreatment and later psychological distress among college students: The mediating role of maladaptive schemas. Journal of Child Abuse and Neglect, 33(1), 59-68.

Young J.E (1990), Scales schema-focused. New York, Guilford Press. 